\title{
An investigation of motor learning during side- step cutting, design of a randomised controlled trial
}

\author{
Anne Benjaminse ${ }^{1,2^{*} \dagger}$, Koen APM Lemmink ${ }^{1,2}$, Ron L Diercks ${ }^{3}$, Bert Otten ${ }^{1 \dagger}$
}

\begin{abstract}
Background: Of all athletic knee injuries an anterior cruciate ligament $(\mathrm{ACL})$ rupture results in the longest time loss from sport. Regardless of the therapy chosen, conservative or reconstructive, athletes are often forced to reduce their level of physical activity and their involvement in sport. Moreover, a recent review reported prevalences of osteoarthritis ranging from $0 \%$ to $13 \%$ for patients with isolated ACL-deficient (ACL-D) knees and respectively 21\% to $48 \%$ in patients with combined injuries. The need for ACL injury prevention is clear. The identification of risk factors and the development of prevention strategies may therefore have widespread health and economic implications. The focus of this investigation is to assess the role of implicit and explicit motor learning in optimising the performance of a side-step-cutting task.
\end{abstract}

Methods/design: A randomized controlled laboratory study will be conducted. Healthy basketball players, females and males, 18 years and older, with no previous lower extremity injuries, playing at the highest recreational level will be included. Subjects will receive a dynamic feedback intervention. Kinematic and kinetic data of the hip, knee and ankle and EMG activity of the quadriceps, hamstrings and gastrocnemius will be recorded.

Discussion: Female athletes have a significantly higher risk of sustaining an ACL injury than male athletes. Poor biomechanical and neuromuscular control of the lower limb is suggested to be a primary risk factor of an ACL injury mechanism in females. This randomized controlled trial has been designed to investigate whether individual feedback on task performance appears to be an effective intervention method. Results and principles found in this study will be applied to future ACL injury prevention programs, which should maybe more focus on individual injury predisposition.

Trial registration: Trial registration number NTR2250.

\section{Background}

Of all athletic knee injuries an anterior cruciate ligament (ACL) rupture results in the longest time loss from sport [1]. Regardless of the therapy chosen, conservative or reconstructive, athletes are often forced to reduce their level of physical activity and their involvement in sport [2]. Moreover, a recent review reported prevalences of osteoarthritis ranging from $0 \%$ to $13 \%$ for patients with isolated ACL injury and $21 \%$ to $48 \%$ in

\footnotetext{
* Correspondence: a.benjaminse@med.umcg.nl

† Contributed equally

'University Medical Center Groningen, Faculty of Medical Sciences, Center for Human Movement Sciences, University of Groningen, Antonius

Deusinglaan 1, 9713 AV Groningen, The Netherlands

Full list of author information is available at the end of the article
}

patients with combined injuries [3], indicating additional long-term medical expenses [4]. The identification of risk factors and the development of prevention strategies may therefore have widespread health and economic implications.

The majority of research into noncontact ACL injury risk factors and the accompanying gender disparity has focused on the neuromuscular and biomechanical risk factors because of their potential for modification. Neuromuscular training strategies focussing on warm-up, technique, balance, strengthening and agility exercises have continued to evolve and represent an ever-increasing and equally important research focus [5-11]. Recent epidemiological data, however, suggest that in spite of these ongoing initiatives and reported early successes 
$[5,8,12,13]$, ACL injury rates and the associated gender disparity have not diminished [14-16]. The disparity between positive laboratory results and actual effects on injury outcomes in high-risk female populations suggests a missing link between current research and clinical applications for neuromuscular training interventions [17]. One problem could be the difficulties with the measurements of injury rates and the difficulties with the implementation of thorough large scale injury prevention programs. Another issue could be the fact that the transition from conscious awareness during training sessions to unexpected and automatic movements during a training or game involves complicated motor control adaptations. Post-intervention lower extremity positions in the laboratory do not necessary reflect those on the field. The transition from conscious awareness during training sessions on technique in the laboratory to unexpected and automatic movements during a training or game involves complicated motor control adaptation. The purpose of this research project is to highlight the issue of motor learning in optimising sports performance in a manner consistent with ACL injury prevention.

Instructions can be an effective means of conveying goal-related information and educators commonly use them to teach and refine motor performance at all levels of skill [18]. During our intervention we will use the concept of implicit and explicit learning. Implicit motor learning refers to the acquisition of a motor skill without the concurrent acquisition of explicit knowledge about the performance of a skill that is normally processed in an automatic way, while explicit motor learning does refer to acquiring motor skills with an internal focus and specific knowledge about the performance of a skill [19]. The performance and learning of motor skills has been shown to be enhanced if the performer adopts an external focus of attention (focus on the movement effect) compared to an internal focus (focus on the movements themselves) [20].

There are ACL injury prevention programs addressing explicit rules regarding desired landing positions by emphasizing proper alignment of the hip, knee, and ankle [8-12,21-28]. However, the use of explicit strategies may be unsuitable for the control of complex motor skills [19]. It has been shown, that instructions that direct performers' attention to his or her own movements can actually have a detrimental effect on performance and learning and disrupt the execution of automatic skills, particularly in comparison with an externally directed attentional focus [20,29-32]. The exact reasons for the beneficial effects of an external focus of attention are still relatively unclear. However, trying to consciously control one's movements might interfere with the normal, automatic motor control processes, leading to a breakdown in the natural coordination of the movement $[32,33]$. Motor skills that are acquired explicitly tend to be less resilient under psychological [33-37] and physiological pressure [38,39], tend to interfere with the normal automatic processing of the motor schema $[33,40]$, tend to be less durable [41] and less robust [42] when a fast response is required and explicit learning may be affected to a greater extent by an individual's intelligence than implicit learning [43-45]. Taking these benefits into account, implicit learning should be made more appealing in modern sporting arenas, since motor skills are often performed in anxiety-provoking competitions, under fatigued conditions. Having to consciously control a movement is considered to be a great disadvantage for athletes where attention to the game, players and ball and fast acting is required and thus very little or no attention could be given to a most optimal lower extremity position. A high-cognitive task will be vulnerable during a game.

In the ACL injury enigma in particular, psychological and physiological pressure is an important factor. Myklebust et al. reported that athletes are at a higher risk of suffering an ACL injury during a game than during practice [9]. Fatigue has also been proposed to be a contributor to non-contact ACL injuries [46-48]. For obvious reasons, a game constitutes more psychological and physiological stress compared to a practice session. Especially in later stages of competition, fatigue may have a cumulative, unfavorable effect on neuromuscular control and may potentially result in hazardous movement strategies [49]. The decreased capacity for controlling body movements after fatigue will potentially be more prominent when appropriate landing techniques have been taught in an explicit manner. Also, the possibility that implicit learning may immunize the athlete against the often debilitating influence of psychological stress on motor output should not be ignored.

Considering the benefits of implicit learning mentioned above, we feel that in the prevention of ACL injuries, we need to discover the possibilities of implicit learning. We use visual feedback (ie. observational learning) during our trial, where imitation of what is shown plays an important role. Imitation is the copying of body movements that is observed [50]. The human mirror system forms the foundation of observational learning [51]. Mirror neurons mediate understanding of action because neurons that represent an action are activated in the observer's premotor cortex. This automatically induced, motor representation of the observed action corresponds to that which is spontaneously generated during active action and whose outcome is known to the acting individual. Mirror neurons are visuomotor neurons that fire both when 
an action is performed and when a similar or identical action is passively observed [52]. A template of the movement becomes active through the mirror neurons by which the movement itself becomes clear in terms of motor actions, without high cognitive reflections [53]. This automatically induced, motor representation of the observed action corresponds to that which is spontaneously generated during active action and whose outcome is known to the acting individual. An important functional aspect of mirror neurons is therefore the relation between their ability to link visual and motor properties.

When observers see a motor event that shares features with a similar motor event present in their motor repertoire, they are primed to repeat it. The greater the similarity between the observed event and the motor event, the stronger the priming is [54]. The activation of motor representations through mere observation could have important applications in enhancing skill learning and in motor rehabilitation [55]. We therefore want to apply an intervention in which the subjects see their own performance, implicitly or explicitly. Priming will be strong, as seeing one's own performance will result in great similarity between the observed event and the executed event.

The goal of this research project is to investigate how we can train athletes individually to use certain motor patterns, that eventually become automatic. Motor learning that is offered in an implicit manner, will potentially be more robust once on the field. Our research project might give more insight in the ongoing problem of ACL injuries and might give the opportunity to more effectively implement prevention programs targeted towards the individual needs. If individual visual implicit feedback on task performance appears to be an effective intervention method, this could be applied to larger populations participating in team sports with a high risk of sustaining an ACL injury. Results and principles found in this study will be applied to future ACL injury prevention programs.

\section{Methods/Design}

\section{Study design}

This will be a randomised controlled laboratory study with two between-subject factors (gender and intervention group (ie. implicit, explicit and control group)) and one within-subject factor (time, ie. pretest, one week posttest and one month posttest). After consent to participate, subjects will be randomly assigned to a group based on the order in which they sign up for the initial baseline testing session. As an equal number of males and females per group $(2 \times$ intervention group and $1 \times$ control group) is essential, stratified sampling will be carried out. The study design, procedures and informed consent are approved by the local Medical Ethical Committee (registration number 2009-142).

\section{Study population}

Because the magnitude of the gender discrepancy in ACL injury rate is not consistent across sports [56-58], it is essential to study a specific group of athletes. As basketball is a high risk sport in terms of ACL injury $[14,56,59]$, basketball athletes will be investigated in this study. Basketball players will serve as the control group, which will be an age- and activity level-matched will be included for this study. Inclusion criteria are: 18 years or older, playing basketball at the highest recreational level, no history of major lower extremity injury or surgery, no current or recent (6 months) injury to the entire lower extremity and able to participate in training and games for $100 \%$ at time of testing. Subjects will be excluded if they have had: any hip, knee or other relevant injury in the last 6 months prior to testing, any relevant previous injury or surgery at any joint of the lower extremity or any history of neurological, vestibular or visual impairment. Potential subjects will be recruited from regional basketball clubs and schools. Subjects will contact the primary investigator to schedule the testing session. Prior to testing, the subjects will be screened by the physical therapist (A.B.) on ACL status (ie. lesion, partial lesion, no lesion) The Lachman test and pivot shift test will be performed. The Lachman test has a very high sensitivity (85\%) and specificity (94\%). The pivot shift test is very specific, namely $98 \%$ [60]. In case of a lesion or partial lesion of the ACL, subjects will be excluded from the study. Furthermore, subjects may terminate participation under each circumstance.

We take the knee abduction moment and the loading rate of knee abduction moment over time as the main variables of interest as the main training purpose of this study is to get alignment of the leg in line with the GRF. When taking the clinical relevance of an 'at risk' and a 'not at risk' abduction moment into account, we refer to the prospective study by Hewett et al. [61]. The females in that study who ruptured their ACL $(n=9)$ had a greater stance phase peak external knee abduction moment, $-45.3 \pm 28.5 \mathrm{Nm}$, compared to that of uninjured females $(n=390),-18.4 \pm 15.6 \mathrm{Nm}(\mathrm{P}<0.001)$. We considered this mean difference in knee abduction moment to be clinically relevant, as it was predictive of ACL injury occurrence in a prospective study. We therefore used the difference to calculate the power for this study. With an effect size of 0.55 (determined based on those differences of the means divided by the pooled SD) and an alpha of 0.05 , we reach a power of 0.80 when including 120 subjects, which means 40 subjects (20 females and 20 males) per group (ie. implicit learning group, explicit learning group and control group). 
$\mathrm{G}^{*}$ Power for Mac, Version 3.1.2 has been used to calculate the needed sample size.

\section{Intervention}

Two types of immediate visual feedback will be given (Table 1):

1) Explicit feedback: After each sidestep cutting manoeuvre, subjects will immediately receive explicit instructions to improve their performance. Potential ACL injury risk factors include: 1) Increased knee valgus angle [61], 2) Decreased knee flexion angle [62-64], 3) Increased anterior tibial shear force [65,66], 4) Decreased hip flexion angle $[62,64,67,68], 5)$ Increased hip internal rotation angle [62], 6) Increased knee internal rotation angle [69]. Items to improve these potential risk factors above will be mentioned to the subjects and subjects will be requested to minimise the load at the knee.

2) Implicit feedback: Subjects will undergo a dynamic visual feedback intervention. Each time after a subject has performed the task, a visual representation of the best performance so far of the whole body (3D posterior view) will be shown to the subject with the Basler recordings (Darwinian learning). No explicit feedback or instructions at all will be given, however subjects will know in advance that there are superior and inferior ways to perform the task. The subject will search by him-/herself for the solution that fits best in their body; they explore and then select the performance which fits best.

The best performance so far will be based on the peak valgus moment, which needs to be as low as possible. The total training session consists of 30 trials. As we need to make sure that the improvements in landing performance (if any) are permanent rather than temporary, a retention test will be conducted one week (similar to Onate et al.) [70] and one month later. During the retention tests no feedback at all will be given to either group. The control group will perform the exact same tasks as the intervention groups. The control group, however, will not receive any feedback during any trial. To make sure three homogeneous groups are participating, five trials with no feedback will be performed prior to the real intervention (ie. in addition to the 30 trials).

\section{Measurements}

Screening for inclusion and exclusion criteria will occur at the laboratory setting and will be performed by the primary investigator (A.B.) of this study. All subjects will sign an informed consent form in accordance with the University of Groningen Medical Ethics Committee prior to participation.

Lower extremity kinematic, kinetic and EMG data of subjects performing a sidestep-cutting manoeuvre in the laboratory will be analysed. The primary outcome measurements will be as follows:

1) Knee abduction moment

2) Loading rate of knee abduction moment over time

Secondary outcome parameters will be as follows:

3) Average EMG pattern of the gluteus maximus (GM), vastus medialis (VM), vastus

lateralis $(\mathrm{VL})$, medial hamstring $(\mathrm{MH})$, lateral hamstring (LH), medial gastrocnemius

(MG) and lateral gastrocnemius (LG)

4) Muscle onset time (ie. the first burst in EMG as detected by the Santello algoritm prior

to landing [66]) of the GM, VM, VL, MH, LH, MG and LG

5) Muscle activity of the GM, VM, VL, MH, LH, MG and LG integrated over the interval from 100 milliseconds prior to foot contact to foot contact (preparatory interval) and from foot contact to the point of peak knee flexion (weight acceptance)

6) Muscle co-contraction (ie. using the integrated EMG of each muscle and the formula: [(less active muscle/more active muscle) $\mathrm{X}$ (sum of the integrated activity of both muscles)]) of VL-MG, VL-LH, VM-LG and $\mathrm{VM}-\mathrm{MH}$ over the interval from 100 milliseconds prior to foot contact to foot contact (preparatory interval) and from foot contact to the point of peak knee flexion (weight acceptance)

Table 1 Testing schedule

\begin{tabular}{|c|c|c|c|}
\hline & $\begin{array}{l}\text { Explicit Learning } \\
\text { Group }(n=40)\end{array}$ & Implicit Learning Group $(n=40)$ & $\begin{array}{l}\text { Control } \\
\text { Group }(n=40)\end{array}$ \\
\hline $\begin{array}{l}\text { T1 } \\
\text { Intervention }\end{array}$ & $\begin{array}{l}30 \text { side-step cutting trials - } \\
\text { Detailed verbal instructions on } \\
\text { performance will be given }\end{array}$ & $\begin{array}{l}30 \text { side-step cutting trials - Best } \\
\text { performance will be shown }\end{array}$ & $\begin{array}{l}30 \text { side-step cutting trials - } \\
\text { No feedback on performance } \\
\text { will be given }\end{array}$ \\
\hline $\begin{array}{l}\text { T2 } \\
\text { Retention test (one week post } \\
\text { intervention) }\end{array}$ & $\begin{array}{l}30 \text { side-step cutting trials - } \\
\text { No feedback on performance will be } \\
\text { given }\end{array}$ & $\begin{array}{l}30 \text { side-step cutting trials - } \\
\text { No feedback on performance will be } \\
\text { given }\end{array}$ & $\begin{array}{l}30 \text { side-step cutting trials - } \\
\text { No feedback on performance } \\
\text { will be given }\end{array}$ \\
\hline $\begin{array}{l}\text { T3 } \\
\text { Retention test (one month } \\
\text { post intervention) }\end{array}$ & $\begin{array}{l}30 \text { side-step cutting trials - } \\
\text { No feedback on performance will be } \\
\text { given }\end{array}$ & $\begin{array}{l}30 \text { side-step cutting trials - } \\
\text { No feedback on performance will be } \\
\text { given }\end{array}$ & $\begin{array}{l}30 \text { side-step cutting trials - } \\
\text { No feedback on performance } \\
\text { will be given }\end{array}$ \\
\hline
\end{tabular}


7) Hip, knee and ankle angles at IC, peak posterior GRF and the maximum values for each of those variables

a. Abduction/adduction

b. Flexion/extension

c. External/internal rotation (only for hip and knee)

8) Knee angular displacement flexion angle

9) Joint moments of hip, knee and ankle at IC, peak posterior GRF and the maximum values for each of those variables

a. Abduction/adduction (not for knee, see primary outcome measurement)

b. Flexion/extension

c. External/internal rotation (only for hip and knee)

In addition we will record the history on injuries and/ or surgeries, the Tegner activity level questionnaire $[69,70]$ and activity between intervention and follow up tests.

\section{Subject preparation}

In order to calculate the hip, knee and ankle joint angles and moments, anthropometric measurements will first be taken in preparation of the 3D motion analysis testing. Anthropometric measurements will include body weight and height, knee and ankle diameter and leg length (ASIS - medial malleolus). Subjects will then have reflective markers placed over the heel, lateral malleolus, second metatarsal head, femoral epicondyle and ASIS and PSIS bilateral. Another four markers will be placed bilaterally on the lateral side of the mid-thigh and mid-calf. EMG signals will be recorded using silversilver chloride, pre-gelled bipolar surface electrodes (ZeroWire EMG, Aurion, Italy). Electrode locations will be located via palpation of the subject's anatomy and will be placed over the appropriate muscle belly in line with the direction of the fibres with an interelectrode distance of approximately $20 \mathrm{~mm}$, which is in accordance with the work of Delagi and Perotto [71]. Electrode sites will be shaved, abraded and cleaned with isopropyl alcohol to reduce impedance. The electrodes will be secured to the subject's skin with tape to minimise motion artefact. Electrode placement will be confirmed through visual inspection of signals on the computer screen using Vicon Nexus Software (Version 1.6, Vicon Motion Systems, Inc., Centennial, CO) during standardised manual muscle testing [29]. Two seconds of maximal voluntary isometric contraction (MVIC) EMG signals will be collected from each muscle before data collection. These data will be processed and used for normalisation of the corresponding muscle's EMG activity during the dynamic task. The same investigator (A.B.) will perform all electrode and marker placements. All the subjects will wear tight-fitting shorts and their own indoor basketball shoes.

An unanticipated cutting task will be carried out in the laboratory. Each athlete will complete a practice session that includes several anticipated and unanticipated trials of each of the two tasks to familiarise his-/herself with the experimental setup as well as to reduce the effect of targeting the force platform. The athlete will randomly perform cutting trials. The straight run and cross-step are catch tasks so as to present the athletes with three options. Consequently, the cutting manoeuvre becomes an unanticipated task. Specifically, the cutting manoeuvre consists of an approach run, followed by a plant-and-cut manoeuvre at a $45^{\circ}$ angle with the dominant foot on the force platform. The cutting direction will be to the right for leftfooted subjects and to the left for right-footed subjects. Each angle will be measured from the centre of the force plate and the corresponding line will be marked (using tape) so that it can be clearly seen by the subjects. As for the straight ahead run, the subjects continue the approach run through the experimental setup, with a change in neither direction nor speed.

Two infrared timing gates will be used to ensure that the approach speed will be $4.5-5.5 \mathrm{~m} / \mathrm{s}$ and 0.5 seconds before the subjects land on the force platform and make the cut, a 3-light guiding system will be used to randomly cue the subjects; one light will turn on, indicating the direction the subject should go. Each subject will be given 1 minute between trials to reduce the potential effects of fatigue. To make sure there is pressure on the performance, the exit speeds needs to be $4.0-5.0 \mathrm{~m} / \mathrm{s}$, measured by the infrared timing gaits, 5 meters beyond the force plat form.

Only successful trials will be kept. A cutting trial is deemed successful if the subjects approaches the force platform with the required speed, performs the manoeuvre with the target board illuminating a light, makes IC with the force platform and either runs straight ahead or changes direction at a $45^{\circ}$ cut angle with the required exit speed. Subjects will be required to continue running after sidestep execution for 5 meters. Cutting trials during which the subject modifies his/her stride length (i.e., stutter-step) to make contact with the force platform will also be discarded. The stutter-step will be discarded as these trial will not be comparable with the other trials; the speed will in all likelihood decrease and will not be between 4.5-5.5 m/s anymore. Approach speed is based on previous studies $[69,72]$.

\section{Instrumentation}

Vicon's Nexus software (Version 1.6) of the Vicon Motion Analysis System (Vicon Motion Systems, Inc., 
Centennial, CO) will be used to collect and calculate the kinematic and kinetic data. GRF data will be collected at $1200 \mathrm{~Hz}$ by 2 force plates (Bertec Corporation, Columbus, Ohio) that are located within a custom-built flooring system in which the force plates are flush with the surrounding surface. Surface electromyographic (EMG) signals will be collected with the Noraxon Telemyo Telemetry EMG System (Noraxon USA Inc, Scottsdale, AZ) using ZeroWire. Signals will be passed from the electrodes to the transmission unit. After amplification, the telemetry signals will then be passed from the transmitter to the receiver for further amplification (overall gain of 2000) and filtered with a bandwidth filter $(10 \mathrm{~Hz}$ low pass $500 \mathrm{~Hz}$ high pass Butterworth filter, common mode rejection ratio of $130 \mathrm{db}$ ). Signals from receiver will be collected with the data acquisition package Vicon Nexus Software (Version 1.6, Vicon Motion Systems, Inc., Centennial, $\mathrm{CO}$ ). The analog signal from the EMG receiver will be converted to a digital signal via a DT3010/32 (32 channel, 24 bit) A/D board (Data Translation, Inc., Marlboro, MA). Basler camera's (640 × 480, $210 \mathrm{fps}$, Vicon Motion Systems, Inc., Centennial, CO) with a $25 \mathrm{~mm} \mathrm{C}$-mount lens will be used to collect analog high-speed data.

\section{Data acquisition and statistical analysis}

Hip, knee and ankle joint kinematics will be evaluated at IC, peak posterior GRF and the maximum values for each of those variables. IC will be defined as the point in time when $5 \%$ of the subject's body weight is upon the force plate. The raw coordinate data will be filtered using an optimised cut off frequency.

Raw analog data from the MVICs and synchronised raw analog data (joint kinematic, joint kinetic data and GRF data) from the jump trials will be imported into Matlab (release 12, The MathWorks, Natick, MA) for data processing and identification of the variables of interest. The mean value of each MVIC will be used for normalisation of the EMG during the jump trials. Both the MVIC and trial EMG data will be processed with a linear envelope before filtering by a Butterworth filter (fourth-order, zero-phase shift, cut off frequency of 20 $\mathrm{Hz}$ ).

Raw analog data from the force plates will be used to calculate the GRF data for each jump trial. The raw coordinate data will be filtered using an optimised cut off frequency. The GRF will be filtered using a fourthorder Butterworth filter at a cut off frequency of 100 Hz. The GRF data will be used to calculate the maximum posterior GRF during the initial-stance phase of the jump tasks.

Only the dominant leg will be analysed. In addition to the 30 trials during the intervention and retention tests, all subjects will perform five trials to begin with. These five baseline trials (without feedback) prior to the intervention will be conducted to assure homogeneity across groups on the primary outcome measures (knee abduction moment and the loading rate of knee abduction moment over time). The results of these five trials will be compared to each other using a one-way ANOVA. Multilevel analysis will be applied to examine the within and between subject effects. The learning curve with implicit versus explicit versus no feedback of the primary outcome measures over time will be analysed using SPSS 18.0 (SPSS Inc., Chicago, IL). The secondary outcome measurements will be used as explanatory variables. In addition, post-hoc Bonferroni adjustments will be conducted for the within, between and interaction effects. An alpha level of 0.05 will be set a priori.

\section{Discussion}

Female athletes have a significantly higher risk of sustaining an anterior cruciate ligament (ACL) injury than male athletes. The identification of risk factors and the development of prevention strategies may have widespread health and economic implications. Poor biomechanical and neuromuscular control of the lower limb is suggested to be a primary risk factor of an ACL injury mechanism in females [61]. These are modifiable characteristics, which may potentially reduce the ACL injury rate after proper intervention. But even though a lot of effort is put in the prevention of noncontact ACL injuries, the incidence remains high $[14,15,56]$. The purpose of this research project is to highlight the issue of motor learning in optimising sports performance in a manner consistent with ACL injury prevention. If individual visual feedback on task performance appears to be an effective intervention method, this could be applied to larger populations participating in team sports with a high risk of sustaining an ACL injury. Results and principles found in this study will be applied to future ACL injury prevention programs, which should maybe more focus on individual injury predisposition.

\section{Author details \\ University Medical Center Groningen, Faculty of Medical Sciences, Center for Human Movement Sciences, University of Groningen, Antonius Deusinglaan 1,9713 AV Groningen, The Netherlands. ${ }^{2}$ Hanze University Groningen, University of Applied Sciences, School of Sports Studies, SportsFieldLab Groningen, Zernikeplein 11, 9747 AS, Groningen, The Netherlands. ${ }^{3}$ Department of Orthopaedic Surgery, University Medical Center Groningen, University of Groningen, PO Box 30.001, 9700 RB, Groningen, The Netherlands.}

\section{Authors' contributions}

$A B$ wrote the manuscript, designed the study, coordinates the trial, will collect, analyse and report the data. $\mathrm{BO}$ will assist in analysing and reporting the data. BO, KAPML and RLD designed the study. All authors read, edited and approved the final manuscript. 


\section{Competing interests}

The authors declare that they have no competing interests.

Received: 13 March 2010 Accepted: 13 October 2010

Published: 13 October 2010

\section{References}

1. Hootman JM, Dick R, Agel J: Epidemiology of collegiate injuries for 15 sports: summary and recommendations for injury prevention initiatives. J Athl Train 2007, 42:311-319.

2. Daniel DM, Stone ML, Dobson BE, Fithian DC, Rossman DJ, Kaufman KR: Fate of the acl-injured patient. A prospective outcome study. Am J Sports Med 1994, 22:632-644.

3. Oiestad BE, Engebretsen L, Storheim K, Risberg MA: Knee osteoarthritis after anterior cruciate ligament injury: a systematic review. Am J Sports Med 2009, 37:1434-1443.

4. Gillquist J, Messner K: Anterior cruciate ligament reconstruction and the long-term incidence of gonarthrosis. Sports Med 1999, 27:143-156.

5. Caraffa A, Cerulli G, Projetti M, Aisa G, Rizzo A: Prevention of anterior cruciate ligament injuries in soccer. A prospective controlled study of proprioceptive training. Knee Surg Sports Traumatol Arthrosc 1996, 4:19-21.

6. Chimera NJ, Swanik KA, Swanik CB, Straub SJ: Effects of plyometric training on muscle-activation strategies and performance in female athletes. J Athl Train 2004, 39:24-31.

7. Lephart SM, Abt JP, Ferris CM, Sell TC, Nagai T, Myers JB, Irrgang JJ: Neuromuscular and biomechanical characteristic changes in high school athletes: a plyometric versus basic resistance program. Br I Sports Med 2005, 39:932-938.

8. Mandelbaum BR, Silvers HJ, Watanabe DS, Knarr JF, Thomas SD, Griffin LY, Kirkendall DT, Garrett W Jr: Effectiveness of a neuromuscular and proprioceptive training program in preventing anterior cruciate ligament injuries in female athletes: 2-year follow-up. Am J Sports Med 2005, 33:1003-1010.

9. Myklebust G, Engebretsen L, Braekken IH, Skjolberg A, Olsen OE, Bahr R: Prevention of anterior cruciate ligament injuries in female team handball players: a prospective intervention study over three seasons. Clin J Sport Med 2003, 13:71-78.

10. Olsen OE, Myklebust G, Engebretsen L, Holme I, Bahr R: Exercises to prevent lower limb injuries in youth sports: cluster randomised controlled trial. BMJ 2005, 330:449.

11. Pollard CD, Sigward SM, Ota S, Langford K, Powers CM: The influence of in-season injury prevention training on lower-extremity kinematics during landing in female soccer players. Clin I Sport Med 2006, 16:223-227.

12. Hewett TE, Stroupe AL, Nance TA, Noyes FR: Plyometric training in female athletes. Decreased impact forces and increased hamstring torques. Am J Sports Med 1996, 24:765-773.

13. Silvers HJ, Mandelbaum BR: Prevention of anterior cruciate ligament injury in the female athlete. Br J Sports Med 2007, 41(Suppl 1):i52-59

14. Agel J, Arendt EA, Bershadsky B: Anterior cruciate ligament injury in national collegiate athletic association basketball and soccer: a 13-year review. Am J Sports Med 2005, 33:524-530.

15. Griffin LY, Albohm MJ, Arendt EA, Bahr R, Beynnon BD, Demaio M, Dick RW, Engebretsen L, Garrett WE Jr, Hannafin JA, Hewett TE, Huston L, Ireland ML, Johnson RJ, Lephart S, Mandelbaum BR, Mann BJ, Marks PH, Marshall SW, Myklebust G, Noyes FR, Powers C, Shields C Jr, Shultz SJ, Silvers H, Slauterbeck J, Taylor DC, Teitz CC, Wojtys EM, Yu B: Understanding and preventing noncontact anterior cruciate ligament injuries: a review of the Hunt Valley II meeting, January 2005. Am J Sports Med 2006, 34:1512-1532.

16. Renstrom P, Ljungqvist A, Arendt E, Beynnon B, Fukubayashi T, Garrett W, Georgoulis T, Hewett TE, Johnson R, Krosshaug T, Mandelbaum B, Micheli L, Myklebust G, Roos E, Roos H, Schamasch P, Shultz S, Werner S, Wojtys E, Engebretsen $\mathrm{L}$ : Non-contact $\mathrm{ACL}$ injuries in female athletes: an International Olympic Committee current concepts statement. Br J Sports Med 2008, 42:394-412.

17. Myer GD, Ford KR, Brent JL, Hewett TE: Differential neuromuscular training effects on $A C L$ injury risk factors in"high-risk" versus "low-risk" athletes. BMC Musculoskelet Disord 2007, 8:39.

18. Hodges NJ, Franks IM: Modelling coaching practice: the role of instruction and demonstration. J Sports Sci 2002, 20:793-811.
19. Maxwell JP, Masters RSW, Eves F: From novice to no know-how: a longitudinal study of implicit motor learning. J Sports Sci 2000, 18:111-120.

20. Wulf G, Prinz W: Directing attention to movement effects enhances learning: a review. Psychon Bull Rev 2001, 8:648-660.

21. Hewett TE, Lindenfeld TN, Riccobene JV, Noyes FR: The effect of neuromuscular training on the incidence of knee injury in female athletes. A prospective study. Am J Sports Med 1999, 27:699-706.

22. Holm I, Fosdahl MA, Friis A, Risberg MA, Myklebust G, Steen H: Effect of neuromuscular training on proprioception, balance, muscle strength, and lower limb function in female team handball players. Clin J Sport Med 2004, 14:88-94.

23. Irmischer B, Harris C, Pfeiffer R, DeBeliso M, Adams K, Shea K: Effects of a knee ligament injury prevention exercise program on impact forces in women. J Strength Cond Res 2004, 18:703-707.

24. Myer GD, Ford KR, Brent JL, Hewett TE: The effects of plyometric vs. dynamic stabilization and balance training on power, balance, and landing force in female athletes. I Strength Cond Res 2006, 20:345-353.

25. Myer GD, Ford KR, McLean SG, Hewett TE: The effects of plyometric versus dynamic stabilization and balance training on lower extremity biomechanics. Am J Sports Med 2006, 34:445-455.

26. Noyes FR, Barber-Westin SD, Fleckenstein C, Walsh C, West J: The dropjump screening test: difference in lower limb control by gender and effect of neuromuscular training in female athletes. Am J Sports Med 2005, 33:197-207.

27. Petersen W, Braun C, Bock W, Schmidt K, Weimann A, Drescher W, Eiling E, Stange R, Fuchs T, Hedderich J, Zantop T: A controlled prospective case control study of a prevention training program in female team handball players: the German experience. Arch Orthop Trauma Surg 2005, 125:614-621

28. Pfeiffer RP, Shea KG, Roberts D, Grandstrand S, Bond L: Lack of effect of a knee ligament injury prevention program on the incidence of noncontact anterior cruciate ligament injury. J Bone Joint Surg Am 2006, 88:1769-1774.

29. Wulf $G$, Lauterbach $B$, Toole $T$ : The learning advantages of an external focus of attention in golf. Res Q Exerc Sport 1999, 70:120-126.

30. Wulf $\mathrm{G}$, Weigelt $\mathrm{C}$ : Instructions about physical principles in learning a complex motor skill: to tell or not to tell. Res Q Exerc Sport 1997. 68:362-367.

31. Masters RSW, Poolton JM, Maxwell JP, Raab M: Implicit motor learning and complex decision making in time-constrained environments. J Mot Behav 2008, 40:71-79.

32. McNevin NH, Wulf HG, Carlson C: Effects of attentional focus, self-control, and dyad training on motor learning: implications for physical rehabilitation. Phys Ther 2000, 80:373-385.

33. Masters RSW: Knowledge, "knerves" and know-how: The role of explicit versus implicit knowledge in the breakdown of a complex motor skill under pressure. Br J Psych 1992, 83:343-358.

34. Hardy L, Mullen R, Jones G: Knowledge and conscious control of motor actions under stress. Br J Psychol 1996, 87:621-636.

35. Mullen R, Hardy L, Oldham A: Implicit and explicit control of motor actions: revisiting some early evidence. Br J Psychol 2007, 98:141-156.

36. Beilock SL, Carr TH: On the fragility of skilled performance: What governs choking under pressure? J Exp Psychol: Gen 2001, 130:701-725.

37. Gray R: Attending to the execution of a complex sensorimotor skill: Expertise differences, choking, and slumps. J Exp Psychol: Appl 2004, 10:42-54.

38. Masters RSW, Poolton JM, Maxwell JP: Stable implicit motor processes despite aerobic locomotor fatigue. Conscious Cogn 2008, 17:335-338.

39. Poolton JM, Masters RSW, Maxwell JP: Passing thoughts on the evolutionary stability of implicit motor behaviour: Performance retention under physiological fatigue. Conscious Cogn 2007, 16:456-468.

40. Hardy L, Mullen R, Martin N: Effect of task-relevant cues and state anxiety on motor performance. Percept Mot Skills 2001, 92:943-946.

41. Allen R, Reber A: Very long-term memory for tacit knowledge. Cognition 1980, 8:175-185

42. Turner CW, Fischler IS: Speeded tests of implicit knowledge. J Exp Psychol: Learn Mem Cogn 1993, 19:1165-1177.

43. Reber AS, Walkenfeld FF, Hernstadt R: Implicit and explicit learning individual differences and IQ. J Exp Psychol Learn Mem Cogn 1991, 17:888-896. 
44. Gebauer GF, Nicholas JM: Psychometric Intelligence Dissociates Implicit and Explicit Learning. J Exp Psychol Learn Mem Cogn 2007, 33:34-54.

45. Nemeth D, Janacsek K, Balogh V, Londe Z, Mingesz R, Fazekas M, Jambori S, Danyi I, Vetro A: Learning in Autism: Implicitly Superb. PLoS One 2010, 5: e11731.

46. Hiemstra LA, Lo IK, Fowler PJ: Effect of fatigue on knee proprioception: implications for dynamic stabilization. J Orthop Sports Phys Ther 2001, 31:598-605.

47. Nyland JA, Shapiro R, Caborn DN, Nitz AJ, Malone TR: The effect of quadriceps femoris, hamstring, and placebo eccentric fatigue on knee and ankle dynamics during crossover cutting. J Orthop Sports Phys Ther 1997, 25:171-184.

48. Rodacki AL, Fowler NE, Bennett SJ: Multi-segment coordination: fatigue effects. Med Sci Sports Exerc 2001, 33:1157-1167.

49. McLean SG, Fellin RE, Suedekum N, Calabrese G, Passerallo A, Joy S: Impact of fatigue on gender-based high-risk landing strategies. Med Sci Sports Exerc 2007, 39:502-514.

50. Brass M, Heyes C: Imitation: is cognitive neuroscience solving the correspondence problem? Trends Cogn Sci 2005, 9:489-495.

51. Cattaneo L, Rizzolatti G: The mirror neuron system. Arch Neurol 2009, 66:557-560.

52. Rizzolatti G, Craighero L: The mirror-neuron system. Annu Rev Neurosci 2004, 27:169-192.

53. Rizzolatti G, Fogassi L, Gallese V: Neurophysiological mechanisms underlying the understanding and imitation of action. Nat Rev Neurosci 2001, 2:661-670.

54. Prinz W: Experimental approaches to imitation. In The Imitative Mind Development, Evolution and Brain Bases. Edited by: Prinz M. Cambridge, UK: Cambridge Univ. Press; 2002:143-162.

55. Calvo-Merino B, Glaser D, Grèzes J, Passingham R, Haggard P: Action observation and acquired motor skills: an FMRI study with expert dancers. Cereb Cortex 2005, 15:1243-1249.

56. Arendt $E$, Dick R: Knee injury patterns among men and women in collegiate basketball and soccer. NCAA data and review of literature. Am J Sports Med 1995, 23:694-701.

57. Arendt EA, Agel J, Dick R: Anterior cruciate ligament injury patterns among collegiate men and women. J Athl Train 1999, 34:86-92.

58. Mihata $L C$, Beutler Al, Boden BP: Comparing the incidence of anterior cruciate ligament injury in collegiate lacrosse, soccer, and basketball players: implications for anterior cruciate ligament mechanism and prevention. Am J Sports Med 2006, 34:899-904.

59. Prodromos CC, Han Y, Rogowski J, Joyce B, Shi K: A meta-analysis of the incidence of anterior cruciate ligament tears as a function of gender, sport, and a knee injury-reduction regimen. Arthroscopy 2007, 23:1320-1325, e1326

60. Benjaminse A, Gokeler A, van der Schans CP: Clinical diagnosis of an anterior cruciate ligament rupture: a meta-analysis. J Orthop Sports Phys Ther 2006, 36:267-288.

61. Hewett TE, Myer GD, Ford KR, Heidt RS Jr, Colosimo AJ, McLean SG, van den Bogert AJ, Paterno MV, Succop P: Biomechanical measures of neuromuscular control and valgus loading of the knee predict anterior cruciate ligament injury risk in female athletes: a prospective study. Am J Sports Med 2005, 33:492-501.

62. Chappell JD, Creighton RA, Giuliani C, Yu B, Garrett WE: Kinematics and electromyography of landing preparation in vertical stop-jump: risks for noncontact anterior cruciate ligament injury. Am I Sports Med 2007, 35:235-241.

63. Malinzak RA, Colby SM, Kirkendall DT, Yu B, Garrett WE: A comparison of knee joint motion patterns between men and women in selected athletic tasks. Clin Biomech (Bristol, Avon) 2001, 16:438-445.

64. McLean SG, Walker KB, van den Bogert AJ: Effect of gender on lower extremity kinematics during rapid direction changes: an integrated analysis of three sports movements. J Sci Med Sport 2005, 8:411-422.

65. Chappell JD, YU B, Kirkendall DT, Garrett WE: A comparison of knee kinetics between male and female recreational athletes in stop-jump tasks. Am J Sports Med 2002, 30:261-267.

66. Sell TC, Ferris CM, Abt JP, Tsai YS, Myers JB, Fu FH, Lephart SM: Predictors of proximal tibia anterior shear force during a vertical stop-jump. J Orthop Res 2007, 25:1589-1597.

67. Landry SC, McKean KA, Hubley-Kozey CL, Stanish WD, Deluzio KJ: Neuromuscular and lower limb biomechanical differences exist between male and female elite adolescent soccer players during an unanticipated run and crosscut maneuver. Am J Sports Med 2007, 35:1901-1911.

68. Landry SC, McKean KA, Hubley-Kozey CL, Stanish WD, Deluzio KJ: Neuromuscular and lower limb biomechanical differences exist between male and female elite adolescent soccer players during an unanticipated side-cut maneuver. Am J Sports Med 2007, 35:1888-1900

69. McLean SG, Lipfert SW, van den Bogert AJ: Effect of gender and defensive opponent on the biomechanics of sidestep cutting. Med Sci Sports Exerc 2004, 36:1008-1016.

70. Onate JA, Guskiewicz KM, Marshall SW, Giuliani C, Yu B, Garrett WE: Instruction of jump-landing technique using videotape feedback: altering lower extremity motion patterns. Am J Sports Med 2005, 33:831-842.

71. Delagi EF, Perotto A, ed: Anatomic guide for the electromyographer-the limbs. Springfield, III: Thomas, 21980.

72. McLean SG, Huang $X$, van den Bogert AJ: Association between lower extremity posture at contact and peak knee valgus moment during sidestepping: implications for ACL injury. Clin Biomech (Bristol, Avon) 2005, 20:863-870.

\section{Pre-publication history}

The pre-publication history for this paper can be accessed here: http://www.biomedcentral.com/1471-2474/11/235/prepub

doi:10.1186/1471-2474-11-235

Cite this article as: Benjaminse et al: An investigation of motor learning during side-step cutting, design of a randomised controlled trial. $B M C$ Musculoskeletal Disorders 2010 11:235.

\section{Submit your next manuscript to BioMed Central and take full advantage of:}

- Convenient online submission

- Thorough peer review

- No space constraints or color figure charges

- Immediate publication on acceptance

- Inclusion in PubMed, CAS, Scopus and Google Scholar

- Research which is freely available for redistribution
C Biomed Central 